Supporting Information

\title{
Structural Investigation of Sulfonated Polyphenylene Ionomers for the Design of Better Performing Proton Conductive Membranes
}

Keisuke Shiino ${ }^{a}$, Toshiya Otomo $^{b}$, Takeshi Yamada $^{c}$, Hiroshi Arima ${ }^{c}$, Kosuke Hiroi $^{d}$, Shinichi Takata ${ }^{d}$ Junpei Miyake ${ }^{e}$ Kenji Miyatake $e^{e, f, g} *$

a Interdisciplinary Graduate School of Medicine and Engineering, University of Yamanashi, 4 Takeda, Kofu, Yamanashi 400-8510, Japan

${ }^{\mathrm{b}}$ Institute of Materials Structure Science, High Energy Accelerator Research Organization (KEK), Tsukuba, Ibaraki 305-0801, Japan

${ }^{\mathrm{c}}$ Neutron Science and Technology Center, Comprehensive Research Organization for Science and Society, Tokai, Ibaraki, 319-1106, Japan

${ }^{\mathrm{d}}$ Materials \& Life Science Facility Division, J-PARC Center, Japan Atomic Energy Agency, Tokai, Ibaraki, 319-1195, Japan

${ }^{\text {e }}$ Clean Energy Research Center, University of Yamanashi, 4 Takeda, Kofu, Yamanashi 400-8510, Japan. E-mail: miyatake@yamanashi.ac.jp

${ }^{\mathrm{f}}$ Fuel Cell Nanomaterials Center, University of Yamanashi, 4 Takeda, Kofu, Yamanashi 400-8510, Japan

g Department of Applied Chemistry, Waseda University, Tokyo 169-8555, Japan

\section{AUTHOR INFORMATION}

\section{Corresponding Author}

*E-mail:miyatake@yamanashi.ac.jp 


\section{EXPERIMENTAL SECTION}

\section{Materials.}

$m$-Dichlorobenzene, $p$-dichlorobenzene, and 2,5-dichlorobenzenesulfonic acid dihydrate $\left(\mathrm{SP}-\mathrm{H}^{+}\right.$ monomer) were purchased from TCI, Inc. 2,2'-Bipyridine, dimethyl sulfoxide (DMSO) and toluene dehydrate were purchased from Wako. Bis $\left(1,5\right.$-cyclooctadiene)nickel $(0)\left(\mathrm{Ni}(\mathrm{cod})_{2}\right)$, potassium carbonate $\left(\mathrm{K}_{2} \mathrm{CO}_{3}\right)$, sodium hydroxide $(\mathrm{NaOH}), 0.01 \mathrm{M} \mathrm{NaOH}$ aqueous solution, hydrochloric acid, methanol, and DMSO- $d_{6}$ were purchased from Kanto Chemical Co. All reagents were used as received.

\section{Preparation of Sodium 2,5-Dichlorobenzenesulfonate (SP-Na+ monomer).}

A $100 \mathrm{~mL}$ three-neck flask was charged with SP- $\mathrm{H}^{+}$monomer $(19.0 \mathrm{mmol}, 5.00 \mathrm{~g})$ and pure water (20 $\mathrm{mL})$. To the solution, $5 \mathrm{M} \mathrm{NaOH}$ aqueous solution $(5 \mathrm{~mL})$ was added at r.t. Then, the mixture was cooled in an ice bath to precipitate out $\mathrm{SP}-\mathrm{Na}^{+}$monomer as a white solid. The $\mathrm{SP}-\mathrm{Na}^{+}$monomer was collected by filtration and dried at $60{ }^{\circ} \mathrm{C}$ in vacuum to obtain $\mathrm{SP}-\mathrm{Na}^{+}$monomer $(12.6 \mathrm{mmol}, 3.14 \mathrm{~g}$, $66.6 \%$ yield).

\section{Measurements}

${ }^{1} \mathrm{H}(500 \mathrm{MHz})$ NMR spectra were recorded on a JEOL JNM-ECA 500 spectrometer with DMSO- $d_{6}$ as a solvent and tetramethylsilane (TMS) as an internal reference. Molecular weight of the polymers was estimated from GPC equipped with a Jasco MD-4017 UV detector and a Shodex K-805L column at 50 ${ }^{\circ} \mathrm{C}$. DMF containing 0.01 M LiBr was used as an eluent. Molecular weight was calibrated with standard 
polystyrene samples. IEC titration of the membranes was obtained by acid/base titration. A piece of membrane (ca. $20 \mathrm{mg}$ ) was immersed in $2 \mathrm{M} \mathrm{NaCl}$ aqueous solution for $12 \mathrm{~h}$ at r.t. $\mathrm{HCl}$ released by the ion exchange reaction was titrated with standard $0.01 \mathrm{M} \mathrm{NaOH}$ aqueous solution using automatic potentiometric titrator (AT-510, Kyoto electronic manufacturing Co., Ltd.) at r.t. The titration was conducted three times. By averaging, the IEC titration was obtained. For TEM observation, membrane sample was stained in $0.5 \mathrm{M}$ lead (II) acetate aqueous solution, washed with ultrapure water, and dried. The stained membrane sample was embedded in epoxy resin, sectioned to $50 \mathrm{~nm}$ thickness with a Leica microtome Ultracut UCT, and placed on a copper grid. Images were taken on a Hitachi H-9500 TEM with an accelerating voltage of $200 \mathrm{kV}$. SAXS experiment was conducted with a Rigaku NANO-Viewer diffractometer equipped with a temperature/humidity-controllable chamber. The membrane (ca. $150 \mu \mathrm{m}$ ) was equilibrated for at least $2 \mathrm{~h}$ under the tested conditions. The liquid water uptake was measured gravimetrically and volumetrically. The weight and volume of dry membranes was measured after drying under reduced pressure at $40{ }^{\circ} \mathrm{C}$ for $12 \mathrm{~h}$. Then, the membranes were immersed in distilled water at $40{ }^{\circ} \mathrm{C}$ for $1 \mathrm{~h}$. The hydrated membranes were taken out from water. After removal of excess water, the weight and volume of hydrated membranes was measured. The gravimetrical change was calculated from the following equation: $\left(\mathrm{W}_{\text {wet }}-\mathrm{W}_{\text {dry }}\right) / \mathrm{W}_{\text {dry }} \times 100 \%$, where $\mathrm{W}_{\text {wet }}$ was the weight of the wet membrane and $\mathrm{W}_{\text {dry }}$ was the weight of the dry membrane, and the volumetrically changes was calculated from as follows: $\left(\mathrm{V}_{\text {wet }}-\mathrm{V}_{\text {dry }}\right) / \mathrm{V}_{\text {dry }} \times 100 \%$, where $\mathrm{V}_{\text {wet }}$ was the volume of the wet membrane and $\mathrm{V}_{\text {dry }}$ 
was the volume of the dry membrane. Water uptake and proton conductivity of the membranes from vaper phase were measured simultaneously at $80{ }^{\circ} \mathrm{C}$ with a solid electrolyte analyzer system (MSBAD-V-FC, Bel Japan Co.) equipped with a temperature/humidity-controllable chamber. Weight of the membranes was measured with a magnetic suspension balance at a given humidity, and the water uptake was calculated using the following equation: (weight of hydrated membrane - weight of dry membrane) / weight of dry membrane $\times 100$. Drying at $80{ }^{\circ} \mathrm{C}$ for $3 \mathrm{~h}$ under reduced pressure gave the weight of dry membrane, and exposure to a given humidity for at least $2 \mathrm{~h}$ gave the weight of hydrated membrane. Proton conductivity was measured with a four probe conductivity cell equipped with a Solartron 1255B and SI 1287 impedance analyzers in the same chamber. Ion conducting resistances (R) were determined from the impedance plot obtained in the frequency range from 1 to $10^{5} \mathrm{~Hz}$. The proton conductivity $(\sigma)$ was calculated from the equation: $\sigma=l /(\mathrm{A} \times \mathrm{R})$, where A and 1 are the conducting area and the electrode distance, respectively. Stress-strain curves were obtained by a Shimadzu AGS-J 500N universal test machine attached with a Toshin Kogyo Bethel-3A temperature/humidity-controllable chamber. The membrane sample was cut into a dumbbell shape (DIN-53504-S3, $35 \times 6 \mathrm{~mm}$ (total) and $12 \times 2 \mathrm{~mm}$ (test area)). The measurement was carried out at $80{ }^{\circ} \mathrm{C}$ and $60 \% \mathrm{RH}$ at a tensile rate of 10 $\operatorname{mm} \min ^{-1}$. 
(a)

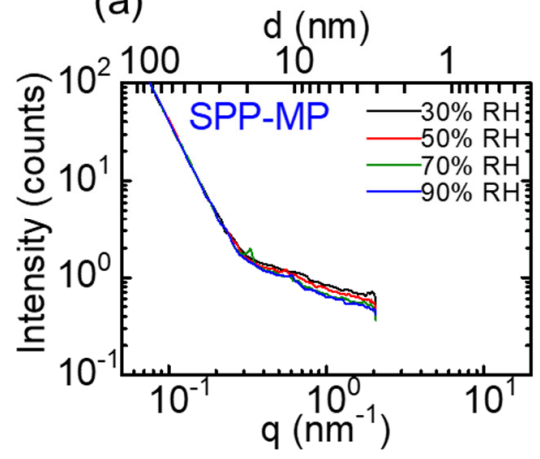

(b)

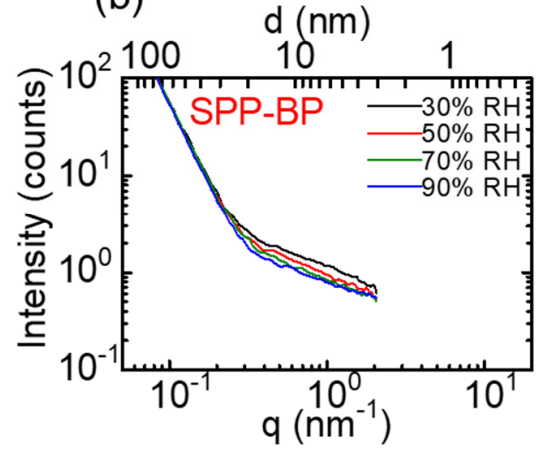

(c)

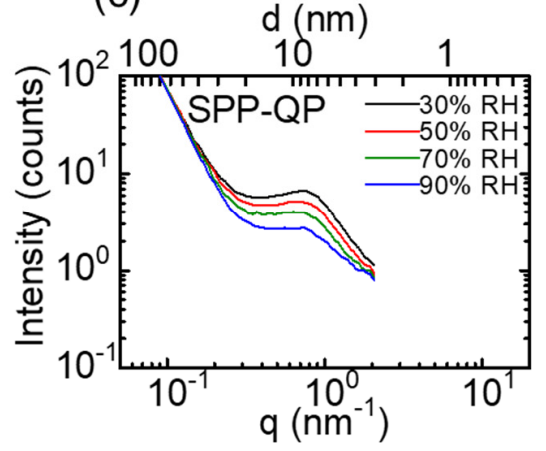

Figure S1. SAXS patterns of (a) SPP-MP, (b) SPP-BP and (c) SPP-QP membranes at $80{ }^{\circ} \mathrm{C}, 30-90 \%$ RH.

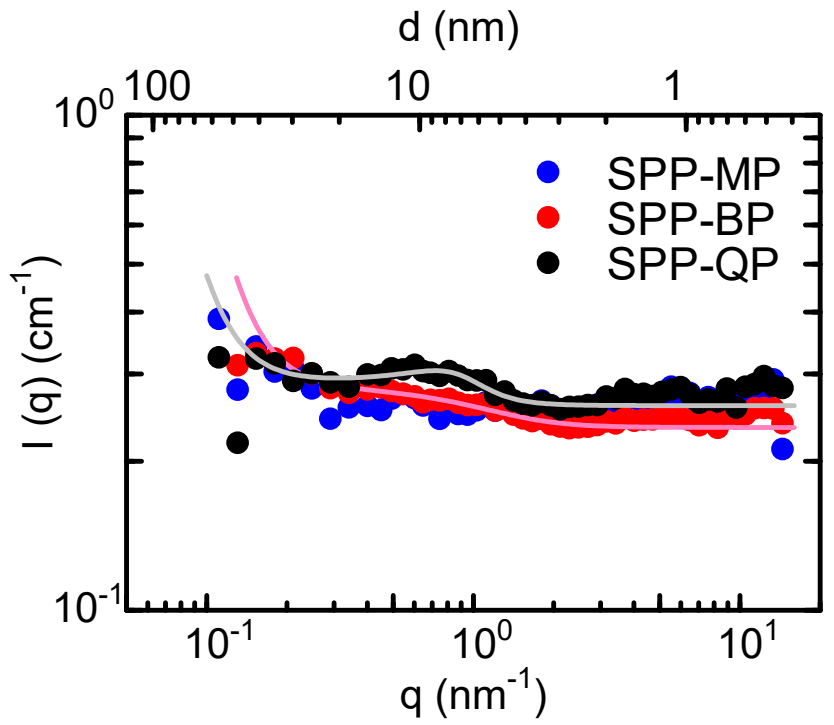

Figure S2. SANS patterns of SPP-MP, -BP and -QP membranes at $80{ }^{\circ} \mathrm{C}, 0 \% \mathrm{RH}\left(\mathrm{D}_{2} \mathrm{O}\right)$. Solid lines for SPP-BP and -QP are fitted results using Eq. (2). 


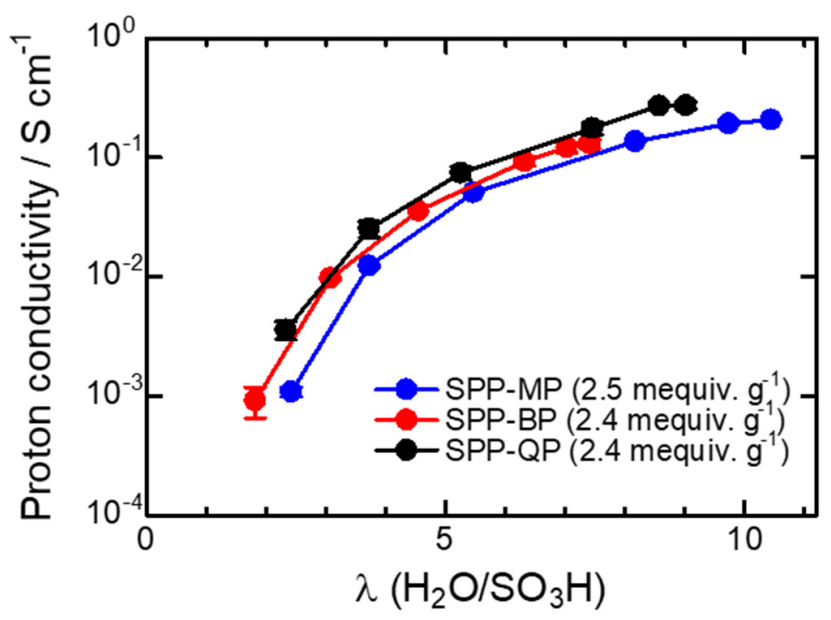

Figure S3. Proton conductivity of SPP-QP, -BP and -MP as a function of number of absorbed water molecules per sulfonic acid group $(\lambda)$. The data for the SPP-QP and -BP were obtained from our previous papers (SPP-QP, Sci. Adv., 2017, 3, eaao0476; SPP-BP, Chem, Commun., 2019, $55,7073)$.

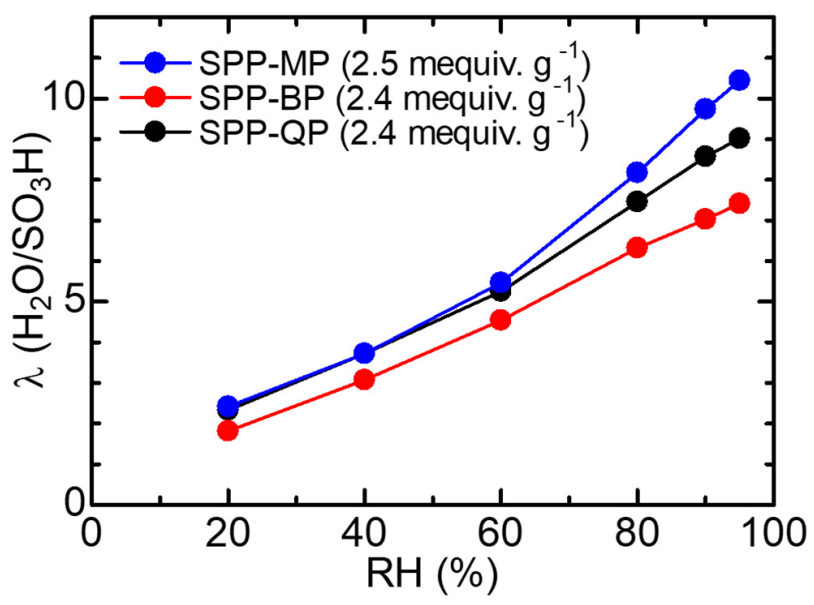

Figure S4. $\lambda$ values of SPP-MP, -BP, -QP membranes at $80{ }^{\circ} \mathrm{C}$ as a function of the relative humidity $(\mathrm{RH})$. 
Table S1. Tensile Properties of SPP-MP, -BP and -QP Membranes at $80{ }^{\circ} \mathrm{C}, 20 \%$ and $60 \%$ RH.

\begin{tabular}{|l|l|l|l|l|l|l|}
$\begin{array}{l}\text { Polymer } \\
\text { Poung's modulus } \\
(\mathrm{GPa})\end{array}$ & $\begin{array}{l}\text { Maximum stress } \\
(\mathrm{MPa})\end{array}$ & $\begin{array}{l}\text { Elongation at break } \\
(\%)\end{array}$ \\
\cline { 2 - 6 } & $20 \% \mathrm{RH}$ & $60 \% \mathrm{RH}$ & $20 \% \mathrm{RH}$ & $60 \% \mathrm{RH}$ & $20 \% \mathrm{RH}$ & $60 \% \mathrm{RH}$ \\
\hline SPP-MP & 1.1 & 1.1 & 54 & 40 & 9 & 11 \\
\hline SPP-BP & 1.1 & 1.4 & 31 & 43 & 4 & 40 \\
\hline SPP-QP & 1.1 & 1.3 & 48 & 41 & 39 & 68 \\
\hline
\end{tabular}

